\title{
Desempenho produtivo e econômico do confinamento de ovinos utilizando diferentes fontes proteicas na ração concentrada
}

\author{
Productive and economic performance of feedlot sheep using different protein sources \\ in concentrate food
}

\author{
ANDRADE, Igo Renan Albuquerque de ${ }^{1 *}$; CÂNDIDO, Magno José Duarte²; \\ POMPEU, Roberto Cláudio Fernandes Franco ${ }^{3}$; GUIMARÃES, Vinícius Pereira ${ }^{3}$; \\ SILVA, Leane Veras da ${ }^{2}$; EVANGELISTA, Monalisa Eva Santos ${ }^{2}$
}

\author{
1Universidade Federal do Ceará, Centro de Ciências Agrárias, Programa de Pós-Graduação em Zootecnia, \\ Fortaleza, Ceará, Brasil. \\ ${ }^{2}$ Universidade Federal do Ceará, Centro de Ciências Agrárias, Departamento de Zootecnia, Fortaleza, \\ Ceará, Brasil. \\ ${ }^{3}$ Embrapa Caprinos e Ovinos, Sobral, Ceará, Brasil. \\ *Endereço para correspondência: igo.renan1 @gmail.com
}

\section{RESUMO}

Objetivou-se avaliar o desempenho produtivo e econômico do confinamento de ovinos mestiços Morada Nova alimentados com diferentes fontes proteicas na ração concentrada em substituição ao farelo de soja. Três diferentes fontes proteicas alternativas foram utilizadas substituindo o farelo de soja: o feno do folíolo da leucena (FFL) e a ureia, ambas substituindo $100 \%$, além da torta de algodão, substituindo em 51,8\% ( $\left.\mathrm{TA}_{51,8}\right)$, com base na matéria seca. Foram avaliados o peso final (PF), o ganho de peso total (GPT), o ganho médio diário (GMD), o número de dias para os cordeiros ganharem $12 \mathrm{~kg}$ (D12) e o desempenho econômico de ovinos confinados e alimentados com diferentes fontes proteicas em substituição ao farelo soja. $\mathrm{O}$ peso corporal inicial foi similar nos cordeiros alimentados com as diferentes fontes proteicas. Ao analisar as variáveis PF, GPT e GMD, pôde-se verificar que os cordeiros alimentados com a ração $\mathrm{TA}_{51,8}$ foram os que obtiveram maiores valores, aliado a um menor D12. Quanto aos indicadores econômicos, o lucro da atividade em $\mathrm{R} \$ / \mathrm{kg}$ de peso corporal (PC) foi maior no confinamento que utilizou a ração $\mathrm{TA}_{51,8}(\mathrm{R} \$ 0,76 / \mathrm{kg} \mathrm{PC})$, seguido pelos que utilizaram farelo de soja ( $\mathrm{R} \$ 0,64 / \mathrm{kg} \mathrm{PC})$, ureia $(\mathrm{R} \$ 0,33 / \mathrm{kg} \mathrm{PC})$ e FFL ( $\mathrm{R} \$ 0,21 / \mathrm{kg} \mathrm{PC})$. Conclui-se que a torta de algodão em substituição ao farelo de soja em $51,8 \%$ é a alternativa alimentar mais atrativa dentre as avaliadas no presente estudo, pois permite uma maior rotatividade do sistema, promovendo uma melhor viabilidade econômica.

Palavras-chave: Leucaena leucocephala, Pennisetum purpureum, torta de algodão, ureia

\section{SUMMARY}

To evaluate the productive and economic performance of the feedlot of Morada Nova crossbred sheep fed different protein sources in concentrate ration to replace soybean meal this study was conducted. Three different alternatives protein sources were used replacing soybean meal: Leucaena leucocephala leaflet hay (FFL) and urea, both replacing $100 \%$, and cottonseed cake, replacing in $51.8 \%\left(\mathrm{TA}_{51,8}\right)$, based on the dry matter. Was evaluated the finale weight $(\mathrm{PF})$, total weight gain (GPT) and average daily gain (GMD), the number of days for the lamb gain $12 \mathrm{~kg}$ (D12) and the economic performance of confined lambs and fed with different alternatives proteins source replacing the soybean meal. The initial body weight was similar in lambs fed different proteins sources. When analyzing the finale weight PF, GPT e GMD, could be verify that the lambs fed with $\mathrm{TA}_{51,8}$ obtained the highest values, combined with a smaller D12. Regarding economic indicators, the gain of activity in $\mathrm{R} \$ / \mathrm{kg} B W$ (body weight) was greater in feedlot that used 
the $\mathrm{TA}_{51,8}(\mathrm{R} \$ 0.76 / \mathrm{kg} \mathrm{PC})$, followed by that used soybean meal (R $\$ 0.64 / \mathrm{kg} \quad \mathrm{PC})$, urea $(\mathrm{R} \$ 0.33 / \mathrm{kg} \mathrm{PC})$ and FFL $(\mathrm{R} \$ 0.21 / \mathrm{kg} \mathrm{PC})$. It is concluded that cottonseed cake in replacing the soybean meal in $51.8 \%$ is the alternative food more attractive among the evaluated in this study, because it allows a greater turnover of the system, promoting a better economic viability.

Keywords: Cottonseed cake, Leucaena leucocephala, Pennisetum purpureum, urea.

\section{INTRODUÇÃO}

A ovinocultura no Nordeste do Brasil é uma atividade de grande importância econômico-social, explorada principalmente para a produção de carne e pele. Nessa mesma região, o rebanho de ovinos cresceu de modo global e tem apresentado índices de crescimento com taxas mais elevadas às de outras regiões (CARVALHO et al., 2006). O semiárido brasileiro caracteriza-se por apresentar um período chuvoso, no qual o alimento nas pastagens é abundante e de boa qualidade nutritiva, enquanto que na época seca as pastagens apresentam baixa capacidade de suporte e baixos valores nutritivos. Devido a esta problemática, cada vez mais o capimelefante tem sido difundido na região, por ser uma gramínea adaptada ao clima, com boa produtividade, onde, a prática da fenação é um dos principais métodos de conservação desta forrageira quando se necessita de um uso imediato e transporte a longas distâncias.

Os sistemas de produção de ovinos no semiárido têm procurado viabilizar o uso de raças adaptadas à região. Segundo Araújo Filho et al. (2010), as raças ovinas para corte apresentam bom acabamento de carcaça, todavia apresentam maiores exigências em alimentação, enquanto que as raças nativas, como o caso do Morada Nova, deixam a desejar em acabamento de carcaça, porém são mais adaptados à região.

Neste contexto, a etapa de confinamento dos ovinos oriundos de uma produção de animais a campo proporcionaria um maior ganho de peso aos animais em menor tempo de engorda, promovendo assim uma maior rotatividade do sistema produtivo. Para que isso ocorra, é necessária uma suplementação com concentrados, que, normalmente, têm preço elevado, aumentando o custo de produção (VÉRAS et al., 2005). Surge, então, a necessidade de estudar a viabilidade de incluir fontes alimentares alternativas e quantificar a resposta animal em termos produtivos e econômicos (CUNHA et al., 2008), proporcionando uma melhor rotatividade do sistema da carne ovina na região.

Diversas são as fontes proteicas alternativas disponíveis no mercado que podem vir a substituir o farelo de soja na ração concentrada, diminuindo o preço de custo da mesma, entre estas fontes merecem destaques o feno do folíolo da leucena (Leucaena leucocephala), a ureia e a torta de algodão.

O presente estudo foi conduzido com o objetivo de avaliar o desempenho produtivo e a viabilidade econômica do confinamento de cordeiros mestiços Morada Nova alimentados com diferentes fontes proteicas na ração concentrada em substituição ao farelo de soja.

\section{MATERIAL E MÉTODOS}

O trabalho foi conduzido no Núcleo de Ensino e Estudos em ForragiculturaNEEF/DZ/CCA/UFC (www.neef.ufc.br) em Fortaleza, Ceará, no período de 
janeiro a abril de 2010. O município de Fortaleza situa-se na zona litorânea a $15,49 \mathrm{~m}$ de altitude, $03^{\circ} 43^{\prime} 02^{\prime \prime}$ de latitude sul, e 38\%32'35" de longitude oeste.

Os animais experimentais foram 20 cordeiros mestiços de Morada Nova, machos, não castrados, provenientes de um mesmo reprodutor, com peso corporal inicial de 18,4 $\pm 1,04 \mathrm{~kg}$ e idade de aproximadamente quatro meses. Antes do início do experimento, os animais selecionados foram vermifugados $\mathrm{e}$ receberam suplementação injetável subcutânea de vitaminas A, D e E. Os mesmos foram confinados em baias coletivas de alvenaria, providas de comedouros e bebedouros, distribuídos em um delineamento inteiramente casualizado, alocando-se cinco animais por baia, onde cada animal representava uma repetição e cada baia representa um tratamento.

Foram realizadas as análises químicas dos ingredientes, dos concentrados experimentais e dos volumosos (Tabela 1), onde, determinaram-se os teores de matéria seca (MS), proteína bruta (PB), fibra em detergente neutro (FDN), fibra em detergente ácido (FDA), extrato etéreo (EE) e cinzas (CINZAS) nas amostras conforme técnicas descritas em Silva e Queiroz (2002). Os carboidratos totais (CT) e seu fracionamento foram obtidos conforme National Research Council (NRC, 2001).

As rações experimentais foram formuladas visando a atender as exigências dos cordeiros, de acordo com o National Research Council (NRC, 2007) para o GMD aproximado de $100 \mathrm{~g}$, compatível com o volumoso utilizado na pesquisa, de baixo valor nutritivo (Tabela 1). As rações foram formuladas mantendo as características isoproteicas e isoenergéticas, com relação volumoso:concentrado de 50:50.

Tabela 1. Composição química dos ingredientes, dos concentrados experimentais e do volumoso (\% MS)

\begin{tabular}{lccccccccccc}
\hline Rações & MS & MM & PB & EE & FDN & FDA & CT & CNF & CF & CNFv & NDT \\
\hline $\begin{array}{l}\text { Farelo de } \\
\text { milho }\end{array}$ & 87,42 & 1,28 & 11,42 & 2,49 & 22,74 & 3,70 & 84,80 & 73,02 & 11,79 & 62,59 & 83,47 \\
$\begin{array}{l}\text { Farelo de } \\
\text { trioo }\end{array}$ & 88,04 & 6,68 & 22,01 & 2,30 & 51,45 & 15,10 & 69,01 & 26,19 & 42,81 & 21,43 & 64,52 \\
$\begin{array}{l}\text { Farelo de } \\
\text { soia }\end{array}$ & 88,24 & 6,49 & 53,29 & 3,20 & 24,03 & 10,35 & 37,02 & 36,21 & 0,81 & 17,26 & 79,63 \\
$\begin{array}{l}\text { Feno do } \\
\text { folíolo da }\end{array}$ & 87,77 & 5,76 & 29,80 & 4,19 & 33,75 & 16,38 & 60,26 & 49,24 & 11,02 & 32,20 & 68,83 \\
Leucena & & & & & & & & & & & \\
LEU $_{100}$ & 88,06 & 5,15 & 12,67 & 4,00 & 40,48 & 7,62 & 78,18 & 45,82 & 32,35 & 38,98 & 74,12 \\
TA $_{51,8}$ & 88,43 & 4,96 & 14,11 & 3,31 & 42,37 & 8,97 & 77,63 & 39,72 & 37,90 & 35,33 & 72,94 \\
SOJ $_{100}$ & 87,91 & 3,86 & 14,39 & 3,82 & 31,89 & 4,12 & 77,93 & 51,02 & 26,90 & 46,15 & 80,74 \\
UR $_{100}$ & 86,64 & 3,75 & 14,29 & 3,27 & 31,76 & 3,00 & 78,69 & 51,33 & 27,36 & 46,57 & 80,18 \\
Feno de & 85,51 & 7,37 & 5,89 & 1,15 & 85,52 & 50,29 & 85,57 & 3,19 & 82,39 & 0,82 & 45,49 \\
\hline LEU $_{104}$
\end{tabular}

$\mathrm{LEU}_{100}$ : feno do folíolo da leucena (100\% substituindo o farelo de soja), TA $\mathrm{A}_{51,8}$ : torta de algodão $(51,8 \%$ substituindo o farelo de soja), $\mathrm{SOJ}_{100}\left(100 \%\right.$ de farelo de soja como fonte proteica), $\mathrm{UR}_{100}(100 \%$ substituindo o farelo de soja), MS (matéria seca), MM (matéria mineral), PB (proteína bruta), EE (extrato etéreo), FDN (fibra em detergente neutro), FDA (fibra em detergente ácido), NDT (nutrientes digestíveis totais), CT (carboidratos totais), CNF (carboidratos não fibrosos), CF (carboidratos fibrosos), CNFvd (carboidratos não fibrosos verdadeiramente digestíveis). 
Foram avaliadas três diferentes fontes proteicas na ração concentrada em substituição à fonte proteica padrão, o farelo de soja $\left(\mathrm{SOJ}_{100}\right)$, são elas: o feno do folíolo da leucena ( $\left.\mathrm{LEU}_{100}\right)$, a ureia $\left(\mathrm{UR}_{100}\right)$, ambas substituindo $100 \%$ do farelo de soja na matéria natural e a torta de algodão $\left(\mathrm{TA}_{51,8}\right)$, substituindo em $51,8 \%$ do farelo de soja na matéria natural, sendo o máximo de substituição alcançada para que não afetasse a composição químico-bromatológica da ração.

$\mathrm{O}$ alimento foi fornecido, ad libitium, diariamente em duas refeições, às $8 \mathrm{~h}$ (40\% do total ofertado ao dia) e outra às
$17 \mathrm{~h}$ (60\% do total ofertado ao dia), coletando-se no dia seguinte as sobras, que foram pesadas, mantendo-as em torno de $10 \%$. Durante o período experimental os cordeiros foram pesados semanalmente. O ganho médio diário (GMD), o consumo médio de matéria seca (CMS) e o número de dias para que os cordeiros alcançassem $o$ peso final de abate estabelecido em $30 \mathrm{~kg}$ (D12) foram obtidos no final do período de confinamento. A composição centesimal, preço dos ingredientes e custo total para produção das diferentes rações concentradas estão apresentados na Tabela 2.

Tabela 2. Composição centesimal, preço dos ingredientes e custo total para produção das diferentes rações concentradas

\begin{tabular}{|c|c|c|c|c|c|c|c|c|c|}
\hline \multirow[t]{2}{*}{ Ingrediente } & \multirow[t]{2}{*}{$\mathrm{R} \$ / \mathrm{kg}$} & \multicolumn{4}{|c|}{ Composição Centesimal } & \multicolumn{4}{|c|}{$\begin{array}{l}\text { Preço do concentrado } \\
(\mathrm{R} \$ / 100 \mathrm{~kg})\end{array}$} \\
\hline & & $\mathrm{SOJ}_{100}$ & $\mathrm{LEU}_{100}$ & $\mathrm{UR}_{100}$ & $\mathrm{TA}_{51,8}$ & $\mathrm{SOJ}_{100}$ & $\mathrm{LEU}_{100}$ & $\mathrm{UR}_{100}$ & $\mathrm{TA}_{51,8}$ \\
\hline F. milho & 0,57 & 86,40 & 75,65 & 95,66 & 79,70 & 49,25 & 43,12 & 54,53 & 45,43 \\
\hline F. soja & 0,80 & 11,20 & - & - & 5,40 & 8,96 & - & - & 4,32 \\
\hline Ureia & 1,10 & - & - & 1,79 & - & - & - & 1,97 & - \\
\hline F.F.leucena & 0,90 & - & 22,03 & - & - & - & 19,83 & - & - \\
\hline T.algodão & 0,90 & - & - & - & 12,48 & - & - & - & 11,23 \\
\hline C.calcítico & 0,17 & 0,20 & - & 0,12 & 0,19 & 0,03 & - & 0,02 & 0,03 \\
\hline F.bicálcico & 1,20 & 0,20 & 0,46 & 0,44 & 0,37 & 0,24 & 0,55 & 0,53 & 0,44 \\
\hline P.mineral ${ }^{1}$ & 1,32 & 2,00 & 1,86 & 1,99 & 1,86 & 2,64 & 2,46 & 2,63 & 2,46 \\
\hline Total & & 100 & 100 & 100 & 100 & 61,12 & 65,95 & 59,67 & 63,91 \\
\hline
\end{tabular}

F.milho (farelo de milho), F.soja (farelo de soja), F.F.leucena (feno do folíolo da leucena), T.algodão (torta de algodão), C.calcítico (calcário calcítico), F.bicálcico (fosfato bicálcico), P.mineral (Premix mineral), $\mathrm{LEU}_{100}$ : feno do folíolo da leucena (100\% substituindo o farelo de soja), $\mathrm{TA}_{51,8}$ : torta de algodão (51,8\% substituindo o farelo de soja), $\mathrm{SOJ}_{100}$ (100\% de farelo de soja como fonte proteica), $\mathrm{UR}_{100}\left(100 \%\right.$ substituindo o farelo de soja). ${ }^{1}$ Composição: fosfato, 65,0g; cálcio, 160,0g; enxofre, 15,0g; magnésio, 6,5g; sódio, 150,0g; cobalto, 0,125g; zinco, 4,5g; ferro, 1,7g; manganês, 4,5g; iodo, 0,06g; selênio, $0,03 \mathrm{~g}$; flúor, $0,95 \mathrm{~g}$; veículo, $1000 \mathrm{~g}$.

A análise econômica e de investimento do confinamento dos cordeiros alimentados com diferentes fontes proteicas em substituição ao farelo de soja na ração foi realizada com base em simulações, utilizando um número de duzentos cordeiros por lote, devido este ser o número máximo de cordeiros manejados por um único funcionário, resultado observado em simulações realizadas pelo grupo de estudo. $O$ custo das instalações foi calculado como sendo currais de madeira com comedouros, bebedouros e áreas de 
sombra, obedecendo a uma área de 0,8 $\mathrm{m}^{2}$ /animal, onde os cordeiros eram mantidos em confinamento. O preço de venda dos cordeiros na saída do lote foi determinado como sendo o valor mínimo para que o tratamento menos lucrativo tornasse rentável, que foi obtido quando o preço de venda simulado obteve o menor valor presente líquido (VPL) positivo.

Foram calculados os indicadores técnicos e zootécnicos, além de computados todos os custos do sistema de acordo com as simulações estudadas. A metodologia de cálculo de custo se baseou nos métodos de custo operacional e de custo total. (HOFFMAN et al., 1987) O horizonte de análise foi de 10 anos, período utilizado na análise de depreciação das instalações. Para o cálculo da depreciação, utilizou-se o método linear ou das cotas fixas, que proporciona uma depreciação constante. Os custos com as rações foram orçados através da compra de sacos de $60 \mathrm{~kg}$ dos ingredientes utilizados. Os custos com produção de volumosos foram calculados através do custo para a produção do $\mathrm{kg}$ do feno de capim-elefante, levando em consideração a implantação de uma capineira de 1,0 ha de capim elefante e as demais despesas de custeio com o processo de produção e conservação da forragem, tais como adubação, mão de obra familiar, preparo do solo, tratos culturais e implementos. Foi determinado o custo de mão de obra como sendo um salário mínimo vigente no ano de 2010 ( $\mathrm{R} \$ 510,00)$, pagando todos os encargos sociais.

$\mathrm{Na}$ presente pesquisa foi utilizada a mesma composição de custos desenvolvida por Martin et al. (1998) observada no Sistema Integrado de Custos Agropecuários (Custagri), desenvolvido pelo Instituto de Economia Agrícola (IEA), em parceria com o Centro Nacional de Pesquisa Tecnológica em Informática para a Agricultura (CNPTIA/Embrapa).

Os indicadores econômicos e financeiros analisados foram: renda bruta da atividade $-\mathrm{RBA}(\mathrm{R} \$ /$ mês $)=$ produção total em $\mathrm{kg} \mathrm{PC} \times$ preço de venda no mercado; custo operacional efetivo da atividade $-\mathrm{COE}(\mathrm{R} \$ / \mathrm{mês})=$ despesas com operações (manutenção de instalações e máquinas) + despesas com mão de obra contratada + despesas com insumos (alimentação, medicamentos, energia); custo operacional total da atividade - COT $(\mathrm{R} \$ / \mathrm{mês})=\mathrm{COE}+$ outros custos operacionais (mão de obra familiar, depreciação de instalações e máquinas) para o cálculo da depreciação, foi utilizado o método linear ou das cotas fixas.; custo total da atividade - CT $(\mathrm{R} \$$ /ano $)=\mathrm{COT}+$ outros custos fixos (remuneração do capital investido em cordeiros, instalações, máquinas e terras) - para o cálculo da remuneração do capital investido, adotou-se taxa de juros de $6,87 \%$ sobre o valor médio do capital empatado, referente à remuneração anual (nominal descontada a inflação) da caderneta de poupança no ano de 2010; Margem bruta da atividade - MB $(\mathrm{R} \$ / \mathrm{mês})=\mathrm{RBA}$ - COE; Margem líquida da atividade $-\mathrm{ML}(\mathrm{R} \$ /$ mês $)=$ RBA - COT; Lucro da atividade $(\mathrm{R} \$ / \mathrm{mês})=\mathrm{RBA}-\mathrm{CT}$; Custo operacional efetivo ( $\mathrm{R} \$ / \mathrm{kg} \mathrm{PC} / \mathrm{mês})=$ (COE x (RBL/RBA x 100))/produção mensal em kg; Custo operacional total $(\mathrm{R} \$ / \mathrm{kg} \mathrm{PC} / \mathrm{mês})=(\mathrm{COT} \times(\mathrm{RBL} / \mathrm{RBA} \mathrm{x}$ 100))/produção mensal em kg; Custo total $(\mathrm{R} \$ / \mathrm{kg} \quad \mathrm{PC} / \mathrm{mês})=(\mathrm{CT} \quad \mathrm{x}$ (RBL/RBA x 100))/produção mensal em kg; Margem bruta (R $\$ / \mathrm{kg}$ PC/mês) $=$ preço do kg PC - COE; Margem líquida $(\mathrm{R} \$ / \mathrm{kg} \mathrm{PC} / \mathrm{mês})=$ preço do $\mathrm{kg} \mathrm{PC}-$ COT; Lucro $(\mathrm{R} \$ / \mathrm{kg}$ PC/mês $)=$ preço do $\mathrm{kg}$ PC $-\mathrm{CT}$. 
Seguindo a metodologia descrita por Hoffmann et al. (1987), foi utilizada como medida de eficiência a relação benefício/custo $(\mathrm{B} / \mathrm{C})$, que expressa o desempenho global de todos os fatores de produção, além de determinar o valor presente líquido (VPL), que leva em consideração o efeito do tempo sobre os valores monetários (valores reais) utilizando-se a taxa média de juros do mercado (custo de oportunidade do capital). O VPL é a soma de todas as receitas líquidas atualizadas a uma taxa de desconto adequada.

Para cada tratamento, foi calculada a taxa interna de retorno (TIR), que é o percentual de retorno obtido sobre o saldo investido e ainda não recuperado em um projeto de investimento, ou seja, é o percentual que expressa a rentabilidade (retorno) anual média do capital alocado no projeto, durante todo o horizonte de análise do projeto. Matematicamente a TIR é a taxa de juros que torna o valor presente das entradas de caixa igual ao valor presente das saídas de caixa do projeto de investimento, ou seja, é aquela taxa de juros que torna o valor presente líquido igual a zero.

Todos os custos utilizados na simulação foram orçados de acordo com os preços encontrados no mercado de FortalezaCE. No que diz respeito à análise estatística, os dados de desempenho animal foram analisados por meio de análise de variância e teste de comparação de médias, utilizando-se o teste de Tukey, a 5\% de probabilidade. Como ferramenta de auxílio às análises estatísticas, utilizou-se os procedimentos GLM (SAS INSTITUTE, 2011). Todavia a avaliação econômica e de investimentos foram realizadas através de análises descritivas.

\section{RESULTADOS E DISCUSSÃO}

O peso corporal inicial $(\mathrm{kg})$ foi similar ( $\mathrm{P}>0,05)$ nos cordeiros alimentados com as diferentes fontes proteicas (Tabela 3), mostrando assim haver homogeneidade entre os tratamentos no início do experimento. $\mathrm{O}$ peso corporal inicial é considerado satisfatório tendo em vista que ovinos mestiços de Morada Nova em geral entram na fase de terminação com peso entre 18 e $20 \mathrm{~kg}$, devendo ser abatidos quando atingem em média 30kg (COSTA et al., 2011). Na variável GPT (ganho de peso total), os cordeiros alimentados com a ração $\mathrm{TA}_{51,8}$ apresentaram um maior ganho $(\mathrm{P}<0,05)$ em relação àqueles alimentados com $\mathrm{LEU}_{100}$ e $\mathrm{UR}_{100}$, porém, não diferindo $(\mathrm{P}>0,05)$ dos ovinos alimentados com $\mathrm{SOJ}_{100}$. Este maior GPT observado nos cordeiros alimentados com a ração $\mathrm{TA}_{51,8}(153,57 \mathrm{~g} / \mathrm{dia})$ é resultado de um maior GMD (ganho médio diário) e maiores ganhos de pesos têm efeito de fundamental importância no processo produtivo, permitindo que os animais sejam comercializados para o abate mais precocemente. É importante ressaltar que não houve diferenças estatísticas entre os ovinos alimentados com a ração à base de farelo de soja e a ração que substituiu totalmente o farelo de soja pela ureia, sugerindo a possibilidade de substituição total do farelo de soja pela ureia, quando se avalia apenas o desempenho animal, visto que a maior quantidade de farelo de milho utilizado no concentrado irá aumentar a quantidade de carboidratos não fibrosos verdadeiramente digestíveis (CNFvd) da dieta (Tabela 1), o que melhora o aproveitamento da ureia, devido à ocorrência de um sincronismo adequado entre os esqueletos de carbono oriundos dos CNFvd e as moléculas de amônia 
oriunda da quebra das moléculas de ureia no ambiente ruminal. Pires et al. (2004), avaliando a substituição total do farelo de soja por ureia no concentrado de bovinos alimentados com bagaço de cana in natura como volumoso na dieta, com uma relação volumoso:concentrado de 20:80, observaram um maior ganho médio diário na ração que utilizou a ureia como fonte proteica. Podendo inferir que uma quantidade maior de carboidratos solúveis no rúmen pudesse vir a maximizar o uso da ureia. Acedo et al. (2011), analisando três diferentes fontes proteicas (farelo de algodão, farelo de soja e ureia) na alimentação de novilhos em pastejo observou um maior consumo de matéria seca total pelos novilhos que foram alimentados com a ureia como fonte proteica. Os autores relatam que devido a maior quantidade de amido presente na dieta que utilizou apenas a ureia como fonte proteica pode ter proporcionado um sincronismo adequado para disponibilização de nitrogênio e energia para os microrganismos. Portanto, a maior proporção de milho na dieta $\mathrm{UR}_{100}$ (Tabela 2), avaliada no presente estudo, pode ter proporcionado uma fonte adequada de amido, favorecendo a fermentação ruminal.

Tabela 3. Peso Inicial (P.I.), peso final (P.F.), ganho de peso total (G.P.T), ganho médio diário (GMD) e número de dias para um ganho de $12 \mathrm{~kg}$ de peso corporal (D12) para cordeiros alimentados com fontes alternativas de proteína na ração concentrada

\begin{tabular}{lccccc}
\hline \multirow{2}{*}{ Item } & P.I (kg) & GPT (kg) & GMD (g) & P.F $(\mathrm{kg})$ & D12 \\
& $\mathrm{CV}=6,04 \%$ & $\mathrm{CV}=13,00 \%$ & $\mathrm{CV}=13,00 \%$ & $\mathrm{CV}=5,86 \%$ & $\mathrm{CV}=11,11 \%$ \\
\hline $\mathrm{LEU}_{100}$ & $18,00^{\mathrm{A}}$ & $8,68^{\mathrm{B}}$ & $112,66^{\mathrm{B}}$ & $26,78^{\mathrm{B}}$ & $106^{\mathrm{A}}$ \\
$\mathrm{TA}_{51,8}$ & $19,20^{\mathrm{A}}$ & $11,83^{\mathrm{A}}$ & $153,57^{\mathrm{A}}$ & $31,38^{\mathrm{A}}$ & $80^{\mathrm{B}}$ \\
$\mathrm{SOJ}_{100}$ & $18,52^{\mathrm{A}}$ & $10,65^{\mathrm{AB}}$ & $138,31^{\mathrm{AB}}$ & $28,80^{\mathrm{AB}}$ & $88^{\mathrm{AB}}$ \\
$\mathrm{UR}_{100}$ & $18,44^{\mathrm{A}}$ & $8,75^{\mathrm{B}}$ & $113,60^{\mathrm{B}}$ & $26,65^{\mathrm{B}}$ & $106^{\mathrm{A}}$ \\
\hline
\end{tabular}

${ }^{A}$ Valores com sobrescritos diferentes em uma mesma coluna são estatisticamente diferentes de acordo com o teste de Tukey $(\mathrm{P}<0,05)$.

$\mathrm{LEU}_{100}$ : feno do folíolo da leucena ( $100 \%$ substituindo o farelo de soja), $\mathrm{TA}_{51,8}$ : torta de algodão ( $51,8 \%$ substituindo o farelo de soja), $\mathrm{SOJ}_{100}$ (100\% de farelo de soja como fonte proteica), $\mathrm{UR}_{100}$ (100\% substituindo o farelo de soja.

A variável número de dias para os cordeiros ganharem $12 \mathrm{~kg}$ de peso corporal (D12) foi influenciada diretamente pelo GMD (Tabela 3), onde os animais alimentados com a ração $\mathrm{TA}_{51,8}$ apresentaram D12 de 80 dias, diferindo $(\mathrm{P}<0,05)$ dos cordeiros que foram alimentados com as rações $\mathrm{LEU}_{100}$ e UR $\mathrm{UR}_{100}$, (106 dias) em ambos sistemas de confinamento, porém não deferiu $\quad(\mathrm{P}>0,05)$ dos cordeiros alimentados com a ração $S O J_{100}$. Apesar de não haver diferença $(\mathrm{P}>0,05)$ entre os cordeiros alimentados com as rações à base de farelo de soja e torta de algodão, do ponto de vista do investidor é mais interessante utilizar a ração $\mathrm{TA}_{51,8}$, pois diminui em oito dias $\mathrm{o}$ período de confinamento, o que irá proporcionar um maior número de lotes por ano, podendo assim diluir os custos de investimentos.

O menor desempenho dos cordeiros alimentados com a dieta $\mathrm{LEU}_{100} \mathrm{em}$ relação aos alimentados com as demais dietas pode ter ocorrido devido ao menor teor proteico observado nesta ração, devido à queda na qualidade do 
feno do folíolo da leucena durante o período de armazenamento da dieta, bem como ao tanino encontrado neste ingrediente, com valor aproximado de $4,72 \%$ da matéria seca do feno da leucena (POSSENTI et al., 2008). Outro fator que pode ter influenciado no desempenho dos ovinos alimentados com a ração $\mathrm{LEU}_{100}$ é a baixa proteína degradável no rúmen (PDR) encontrada no feno do folíolo da leucena. Pires et al. (2006), avaliando a cinética de degradação ruminal da proteína bruta do feno do folíolo da leucena através da metodologia de incubação ruminal com sacos de náilon, observaram uma degradação ruminal média da proteína bruta variando de 55 a $75 \%$ entre os tempos de 12 e 36 horas, com uma degradação potencial de $86,1 \%$. Santos et al. (1998) mencionam que a simples substituição na dieta de PDR pela proteína não degradável no rúmen (PNDR), não assegura melhora no desempenho, pois poderá causar uma deficiência de PDR, afetando os microrganismos ruminais e diminuindo a degradabilidade da porção fibrosa da dieta, assim, tudo dependerá do valor biológico da fonte proteica utilizada.

Todavia, os melhores resultados apresentados pelos cordeiros que receberam a ração $\mathrm{TA}_{51,8}$ nas diferentes variáveis analisadas podem ser explicados devido a uma relação satisfatória entre PDR e PNDR na ração utilizada. A fração proteica que escapa à degradação microbiana pode suplementar a proteína de origem microbiana que chega ao duodeno e aumentar a concentração de aminoácidos disponíveis no intestino para serem absorvidos. Isto se deve à torta de algodão se caracterizar por ser uma boa fonte de PNDR, tornando-se uma possível fonte de aminoácidos essenciais para os ovinos, apresentando $29,45 \%$ de PDR, com 70,55\% de digestibilidade intestinal da proteína bruta, enquanto que a proteína do farelo de soja apresenta grande concentração de proteínas solúveis, o que a torna facilmente hidrolisável no ambiente ruminal (FELISBERTO, 2011). Portanto, a dieta que utiliza a torta de algodão associada ao farelo de soja $\left(\mathrm{TA}_{51,8}\right)$ proporciona uma excelente fonte de $\mathrm{N}$ para as bactérias ruminais, permitindo uma maior síntese de proteína microbiana, bem como um maior fluxo de proteína verdadeira para o duodeno, podendo assim suprir a demanda de aminoácidos para estes animais em crescimento.

No tocante aos indicadores técnicos obtidos durante a simulação da viabilidade econômica, observou-se que a produção diária de quilograma de peso corporal ( $\mathrm{kg} \mathrm{PC})$, foi maior nos cordeiros alimentados com a ração $\mathrm{TA}_{51,8}$ em relação às demais rações (Tabela 4), necessitando de uma menor área para capineira (ha) e de um menor fornecimento de concentrado para o rebanho, mostrando assim uma melhor eficiência alimentar destes cordeiros proporcionada pela ração utilizada.

A estimativa de custos de implantação do sistema para todos os confinamentos pode ser observada na Tabela 5, onde pôde-se verificar que no sistema que utilizou a $\mathrm{LEU}_{100}$ como fonte proteica alternativa na ração concentrada necessita-se um maior custo de implantação total, devido a uma maior área de capineira necessária para a produção

de volumosos, podendo ser explicado devido a uma maior necessidade de consumo de alimentos para que os cordeiros alcançassem o peso ideal de venda $(30 \mathrm{~kg})$, todavia ao analisar os custos de implantação em $\mathrm{R} \$ / \mathrm{kg}$ PC pode-se observar um menor custo no confinamento que utilizou a torta de algodão como fonte proteica ( $\mathrm{R} \$ 0,124 / \mathrm{kg}$ PC), seguido pela soja 
$(\mathrm{R} \$ 0,136 / \mathrm{kg} \quad \mathrm{PC})$, uréia $(\mathrm{R} \$ 0,163 / \mathrm{kg}$ PC) e feno do folíolo da leucena $(\mathrm{R} \$ 0,165 / \mathrm{kg} \quad \mathrm{PC}), \quad$ devendo-se principalmente a uma maior diluição dos custos de investimento ocasionado pela maior produção em $\mathrm{kg} / \mathrm{PC}$ do cordeiro no confinamento que utilizou a torta de algodão como fonte proteica durante o período de análise.

Tabela 4. Indicadores técnicos e zootécnicos da produção de cordeiros em confinamento alimentados com diferentes fontes proteicas na ração concentrada

\begin{tabular}{lcccc}
\hline \multicolumn{1}{c}{ Indicadores } & $\mathrm{SOJ}_{100}$ & $\mathrm{TA}_{51,8}$ & $\mathrm{UR}_{100}$ & $\mathrm{LEU}_{100}$ \\
\hline \multicolumn{1}{c}{ Indicadores técnicos } & & & & \\
\hline Produção diária de kg PC & 27,66 & 30,71 & 22,72 & 22,54 \\
Área utilizada para capineira (ha) & 0,99 & 0,99 & 1,01 & 1,03 \\
Área utilizável (ha) & 0,02 & 0,02 & 0,02 & 0,02 \\
Área total & 1,01 & 1,01 & 1,04 & 1,05 \\
Fornecimento de concentrado para o rebanho (kg MN/mês) & 2559,40 & 2506,79 & 2704,46 & 2698,66 \\
\hline \multicolumn{1}{c}{ Indicadores zootécnicos } & & & & \\
\hline Produtividade da terra (kg/ha x mês) & 848,17 & 945,02 & 667,07 & 681,53 \\
Produtividade da MO (kg/dia-homem) & 3,69 & 4,10 & 3,01 & 3,03 \\
Produtividade do concentrado (kg PC/kg de MN) & 0,33 & 0,37 & 0,25 & 0,26 \\
\hline
\end{tabular}

$\mathrm{LEU}_{100}$ : feno do folíolo da leucena (100\% substituindo o farelo de soja), $\mathrm{TA}_{51,8}$ : torta de algodão (51,8\% substituindo o farelo de soja), $\operatorname{SOJ}_{100}\left(100 \%\right.$ de farelo de soja como fonte proteica), $\mathrm{UR}_{100}(100 \%$ substituindo o farelo de soja), PC (peso corporal), MN (matéria natural), MO (mão de obra).

Tabela 5. Custos de implantação de sistemas de confinamento de cordeiros alimentados com diferentes fontes proteicas na ração concentrada

\begin{tabular}{lcccccccc}
\hline \multirow{2}{*}{ Item } & \multicolumn{2}{c}{$\mathrm{SOJ}_{100}$} & \multicolumn{2}{c}{$\mathrm{TA}_{51,8}$} & \multicolumn{2}{c}{$\mathrm{UR}_{100}$} & \multicolumn{2}{c}{$\mathrm{LEU}_{100}$} \\
\cline { 2 - 9 } & $\mathrm{R} \$$ & $\mathrm{R} \$ / \mathrm{kg} \mathrm{PC}$ & $\mathrm{R} \$$ & $\mathrm{R} \$ / \mathrm{kg} \mathrm{PC}$ & $\mathrm{R} \$$ & $\mathrm{R} \$ / \mathrm{kg} \mathrm{PC}$ & $\mathrm{R} \$$ & $\mathrm{R} \$ / \mathrm{kg}$ \\
\hline Galp. de eng. & 36828,80 & 0,054 & 36828,80 & 0,049 & 36828,80 & 0,065 & 36828,80 & 0,065 \\
Cent. Manejo & 5000,00 & 0,022 & 5000,00 & 0,020 & 5000,00 & 0,026 & 5000,00 & 0,027 \\
Bebedouro & 320,00 & 0,003 & 320,00 & 0,003 & 320,00 & 0,003 & 320,00 & 0,003 \\
Misturador & 3100,00 & 0,014 & 3100,00 & 0,012 & 3100,00 & 0,016 & 3100,00 & 0,016 \\
Trituradora & 3000,00 & 0,013 & 3000,00 & 0,012 & 3000,00 & 0,016 & 3000,00 & 0,016 \\
Balança & 197,67 & 0,001 & 197,67 & 0,001 & 197,67 & 0,001 & 197,67 & 0,001 \\
Form. Cap. & 5115,75 & 0,023 & 5098,06 & 0,021 & 5229,14 & 0,028 & 5300,18 & 0,028 \\
\hline Subtotal & 53562,22 & 0,130 & 53544,53 & 0,118 & 53675,61 & 0,155 & 53746,65 & 0,157 \\
\hline Outros & 2678,11 & 0,006 & 2677,23 & 0,006 & 2683,78 & 0,008 & 2687,33 & 0,008 \\
\hline Total & 56240,33 & 0,136 & 56221,76 & 0,124 & 56359,39 & 0,163 & 56433,99 & 0,165 \\
\hline
\end{tabular}

Galp. de eng.: Refere-se ao galpão onde os animais eram estabulados, adotando-se piso de cimento com comedores e bebedores de alvenaria, além de telhado de madeira com telhas de barro; Cent. Manejo: Refere-se à instalação utilizada para armazenamento das rações, balança, medicamentos, etc.; Form. Cap.: Formação da capineira; $\mathrm{LEU}_{100}$ : feno do folíolo da leucena (100\% substituindo o farelo de soja); $\mathrm{TA}_{51,8}$ : torta de algodão (51,8\% substituindo o farelo de soja); $\mathrm{SOJ}_{100}(100 \%$ de farelo de soja como fonte proteica); $\mathrm{UR}_{100}(100 \%$ substituindo o farelo de soja). Outros (custos extras, referentes a $5 \%$ dos investimentos), PC (peso corporal). 
Quanto ao custo total de manutenção (Tabela 6), o maior valor foi observado no sistema onde os cordeiros foram alimentados com dieta contendo torta de algodão ( $\mathrm{R} \$ 78978,96 /$ ano), todavia, ao analisarmos os mesmos custos em $\mathrm{R} \$ / \mathrm{kg} \mathrm{PC}$, este sistema de produção foi $o$ que obteve o menor custo $(\mathrm{R} \$ 3,179 / \mathrm{kg} \quad \mathrm{PC})$, devendo-se principalmente ao maior desempenho obtido pelos cordeiros mantidos neste sistema, que proporciona uma maior rotatividade, levando à necessidade da compra de um maior número de animais.

Tabela 6. Custo de manutenção anual de sistema de produção em peso corporal de cordeiros em confinamento alimentados com diferentes fontes proteicas na ração concentrada

\begin{tabular}{|c|c|c|c|c|c|c|c|c|}
\hline \multirow{3}{*}{ Custeio } & \multicolumn{2}{|c|}{$\mathrm{SOJ}_{100}$} & \multicolumn{2}{|c|}{$\mathrm{TA}_{51,8}$} & \multicolumn{2}{|c|}{$\mathrm{UR}_{100}$} & \multicolumn{2}{|c|}{$\mathrm{LEU}_{100}$} \\
\hline & PrTot & PrFin & PrTot & PrFin & PrTot & PrFin & PrTot & PrFin \\
\hline & $\mathrm{R}$ \$/ano & $\mathrm{R} \$ / \mathrm{kg}$ & R\$/ano & $\mathrm{R} \$ / \mathrm{kg}$ & R\$/ano & $\mathrm{R} \$ / \mathrm{kg}$ & R \$/ano & $\mathrm{R} \$ / \mathrm{kg}$ \\
\hline Mão de obra & 7344,00 & 0.324 & 7344,00 & 0,296 & 7344.00 & 0,388 & & 0391 \\
\hline Alime & 18170,80 & 0,803 & 18836,45 & 0,758 & 18184,84 & 0,960 & 20137,54 & 1.071 \\
\hline Equipamentos & 415,70 & 0,018 & 415,70 & 0,017 & 415,70 & 0,022 & 415,70 & 0,022 \\
\hline Medicamentos & 1093,93 & 0,048 & 1200,93 & 0,048 & 915,39 & 0,048 & 908,76 & 0,048 \\
\hline Energia elétrica & 416,10 & 0,018 & 416,10 & 0,017 & 416,10 & 0,022 & 416,10 & 0,022 \\
\hline Assist. técnica & 3060,00 & 0,135 & 3060,00 & 0,123 & 3060,00 & 0,162 & 3060,00 & 0,163 \\
\hline $\begin{array}{l}\text { Compra de } \\
\text { Animais }\end{array}$ & 43455,24 & 1,920 & 47705,78 & 1,920 & 36363,07 & 1,920 & 36099,72 & 1,920 \\
\hline Total & 3955,76 & 268 & 78978,96 & 3,179 & 66699,10 & 3,522 & 68381,81 & 3,637 \\
\hline
\end{tabular}

PrTot: Preço total; PrFin: Preço final; $\mathrm{LEU}_{100}$ : feno do folíolo da leucena (100\% substituindo o farelo de soja), $\mathrm{TA}_{51,8}$ : torta de algodão (51,8\% substituindo o farelo de soja), $\mathrm{SOJ}_{100}$ (100\% de farelo de soja como fonte proteica), $\mathrm{UR}_{100}$ (100\% substituindo o farelo de soja), PC (peso corporal).

A variável compra de animais foi a que representou o maior custo de manutenção em todos os sistemas de confinamento, tendo o custo médio de $\mathrm{R} \$ 1,92 / \mathrm{kg} \quad \mathrm{PC}$ para todos os confinamentos analisados (Tabela 6), sendo no confinamento que utilizou o feno do folíolo da leucena como fonte proteica na ração concentrada o que obteve uma menor percentual por ano nas despesas de custeio (52,79\%), seguido do confinamento que utilizou ureia $(54,52 \%)$, farelo de soja $(58,76 \%)$ e torta de algodão $(60,40 \%)$ (Tabela 7$)$. Isto se deve principalmente à baixa conversão alimentar obtida pelos animais alimentados com o feno do folíolo da leucena como fonte proteica.
Quanto aos indicadores econômicos (Tabela 8), o preço de venda foi limitado pelo tratamento que utilizou o feno do folíolo da leucina como fonte proteica, sendo viável apenas a um preço de venda de $\mathrm{R} \$ 4,21 / \mathrm{kg} \mathrm{PC}$, valor obtido quando o VPL (valor presente líquido) foi o menor valor positivo. A renda bruta $(\mathrm{RB})$ da atividade ( $\mathrm{R} \$ \mathrm{mês})$ foi superior nos cordeiros alimentados com $\mathrm{TA}_{51,8}(\mathrm{R} \$ 8717,07)$, devido ao maior número de cordeiros confinados durante $\mathrm{o}$ ano, proporcionado por um melhor desempenho destes animais, gerando uma maior venda do $\mathrm{kg} / \mathrm{PC}$ do cordeiro em relação aos demais sistemas de confinamento, permitindo assim uma maior $\mathrm{RB}$ da atividade ( $\mathrm{R} \$ / \mathrm{mês}$ ) (Tabela 8). 
Rev. Bras. Saúde Prod. Anim., Salvador, v.15, n.3, p.717-730 jul./set., 2014 http://www.rbspa.ufba.br ISSN 15199940

Tabela 7. Custo de manutenção anual de sistema de produção em peso corporal de cordeiros em confinamento alimentados com diferentes fontes proteicas na ração concentrada (\%/Ano)

\begin{tabular}{|c|c|c|c|c|}
\hline Despesas de custeio & $\begin{array}{l}\mathrm{SOJ}_{100} \\
\% / A n o\end{array}$ & $\begin{array}{c}\mathrm{TA}_{51,8} \\
\% / \text { Ano }\end{array}$ & $\begin{array}{l}\mathrm{UR}_{100} \\
\% / \text { Ano }\end{array}$ & $\begin{array}{l}\mathrm{LEU}_{100} \\
\% / \text { Ano }\end{array}$ \\
\hline Mão de obra & 9,93 & 9,30 & 11,01 & 10,74 \\
\hline Alimentação & 24,57 & 23,85 & 27,26 & 29,45 \\
\hline Máquinas e equipamentos & 0,56 & 0,53 & 0,62 & 0,61 \\
\hline Medicamentos & 1,48 & 1,52 & 1,37 & 1,33 \\
\hline Energia elétrica & 0,56 & 0,53 & 0,62 & 0,61 \\
\hline Assistência Técnica & 4,14 & 3,87 & 4,59 & 4,47 \\
\hline Compras de animais & 58,76 & 60,40 & 54,52 & 52,79 \\
\hline Total & 100,00 & 100,00 & 100,00 & 100,00 \\
\hline
\end{tabular}

Tabela 8. Indicadores econômicos da produção de cordeiros em confinamento utilizando diferentes fontes protéicas na ração concentrada

\begin{tabular}{|c|c|c|c|c|}
\hline Indicadores Econômicos & $\mathrm{SOJ}_{100}$ & $\mathrm{TA}_{51,8}$ & $\mathrm{UR}_{100}$ & $\mathrm{LEU}_{100}$ \\
\hline $\mathrm{RB}$ da atividade ( $\mathrm{R} \$ / \mathrm{mês}$ ) & 7940,39 & 8717,07 & 6644,47 & 6596,35 \\
\hline Preço do PC (R $\$ / k g)$ & 4,21 & 4,21 & 4,21 & 4,21 \\
\hline COE da atividade ( $\mathrm{R} \$ / \mathrm{mês})$ & 5550,98 & 5969,58 & 4946,26 & 5086,48 \\
\hline COT da atividade (R $\$ /$ mês) & 6409,33 & 6827,79 & 5805,50 & 5946,28 \\
\hline CT da atividade (R $\$ /$ mês) & 6731,30 & 7149,66 & 6128,15 & 6269,37 \\
\hline MB da atividade (R\$/mês) & 2389,41 & 2747,49 & 1698,21 & 1509,86 \\
\hline ML da atividade (R\$/mês) & 1531,06 & 1889,29 & 838,97 & 650,06 \\
\hline Lucro da atividade ( $\mathrm{R} \$ / \mathrm{mês})$ & 1209,09 & 1567,42 & 516,31 & 326,98 \\
\hline COE por kg de peso corporal ( $\mathrm{R} \$ / \mathrm{kg} \mathrm{PC})$ & 3,27 & 3,18 & 3,52 & 3,64 \\
\hline COT por kg de peso corporal ( $\mathrm{R} \$ / \mathrm{kg} \mathrm{PC})$ & 3,40 & 3,30 & 3,68 & 3,80 \\
\hline CT por kg de peso corporal (R $\$ / k g$ PC) & 3,57 & 3,45 & 3,88 & 4,00 \\
\hline MB por kg de peso corporal (R $\$ / k g P C)$ & 0,94 & 1,03 & 0,69 & 0,57 \\
\hline ML por kg de peso corporal ( $\mathrm{R} \$ / \mathrm{kgPC})$ & 0,81 & 0,91 & 0,53 & 0,41 \\
\hline Lucro por kg de peso corporal (R $\$ / k g P C)$ & 0,64 & 0,76 & 0,33 & 0,21 \\
\hline
\end{tabular}

$\mathrm{LEU}_{100}$ : feno do folíolo da leucena (100\% substituindo o farelo de soja), $\mathrm{TA}_{51,8}$ : torta de algodão $(51,8 \%$ substituindo o farelo de soja), $\mathrm{SOJ}_{100}$ ( $100 \%$ de farelo de soja como fonte proteica), $\mathrm{UR}_{100}(100 \%$ substituindo o farelo de soja), COE: custo operacional efetivo; ${ }^{2} \mathrm{MO}$ : mão de obra; ${ }^{3} \mathrm{COT}$ : custo operacional total. RB (renda bruta), PC (peso corporal), MB (margem bruta), ML (margem líquida).

O custo operacional efetivo (COE) da atividade (R $\$ /$ mês) foi maior nos empreendimentos que obtiveram um maior número de lotes/ano (Tabela 8), como é o caso do $\mathrm{TA}_{51,8}(\mathrm{R} \$ 5969,58)$ que obteve 4,14 ciclos/ano, seguido do
$\mathrm{SOJ}_{100} \quad(\mathrm{R} \$ 5550,98) \quad$ com $\quad 3,77$ ciclos/ano, necessitando de uma maior compra de animais. Todavia, apesar de apresentar um menor número de ciclos/ano (3,13 ciclos), o confinamento que utilizou o feno do folíolo da leucena 
$\begin{array}{lrrr}\left(\mathrm{LEU}_{100}\right) & \text { como } & \text { fonte } & \text { proteica } \\ \text { apresentou } & \text { um } & \text { maior } & \mathrm{COE}\end{array}$ (R\$5086,48/mês) em relação ao confinamento que utilizou a ureia $\left(\mathrm{UR}_{100}\right)$, que obteve um COE de $\mathrm{R} \$$ 4946,26/mês, com 3,16 ciclos/ano. Isto se deve principalmente a um menor custo de manutenção anual com compra de animais observados no $\mathrm{LEU}_{100}$ em relação ao $\mathrm{UR}_{100}$, todavia, apresentando um maior custo com alimentação em relação aos demais tratamentos.

$\mathrm{O}$ custo operacional total (COT) e o custo total (CT) da atividade (R $\$ /$ mês) apresentaram resposta similar ao $\mathrm{COE}$ ( $\mathrm{R} \$ / \mathrm{mês})$, com maiores valores no sistema de produção que utilizou a ração $\left(\mathrm{TA}_{51,8}\right)$, visto que os custos que diferenciaram o COT do COE foram: mão de obra e a depreciação, já o custo que diferenciou o COT do CT foi: remuneração do capital investido, que foram similares nos diferentes sistemas de produção analisados.

Ao se analisar o lucro da atividade (R \$mês) (Tabela 8), o sistema de produção dos cordeiros alimentados com feno do folíolo da leucena como fonte proteica foi o que apresentou menor lucro (R\$326,98/mês), mostrando assim a menor viabilidade do sistema.

$\mathrm{O}$ lucro da atividade em ( $\mathrm{R} \$ / \mathrm{kg} \mathrm{PC}$ ) foi maior no confinamento que utilizou a torta de algodão ( $\mathrm{R} \$ 0,76 / \mathrm{kg} \quad \mathrm{PC})$, seguido pelos que utilizaram farelo de soja $(\mathrm{R} \$ 0,64 / \mathrm{kg} \mathrm{PC})$, ureia $(\mathrm{R} \$ 0,33 / \mathrm{kg}$ $\mathrm{PC}) \mathrm{e}$ feno do folíolo da leucena $(\mathrm{R} \$ 0,21 / \mathrm{kg} \quad \mathrm{PC}) . \quad$ Portanto, o confinamento que utiliza a torta de algodão permite uma maior variação no preço do peso corporal do cordeiro suprindo os custos sem causar prejuízo ao produtor.

No que diz respeito à análise de sensibilidade (Tabela 9), a relação benefício/custo $(\mathrm{B} / \mathrm{C})$ foi menor no confinamento que utilizou o feno do folíolo da leucena como fonte proteica na ração $(\mathrm{B} / \mathrm{C}=1,00)$, portanto, para cada real investido no sistema acrescenta-se um real na receita, tornando a atividade pouco atrativa do ponto de vista do empresário. Entretanto, do ponto de vista do pequeno produtor, esta atividade tornase viável, pois o mesmo terá uma renda mensal fixa (pró-labore), bem como no horizonte de 10 anos, o produtor terá como lucro as instalações novas, visto que o mesmo paga a depreciação do sistema. Vale ressaltar a fonte alternativa de proteína no concentrado que apresentou a maior relação $\mathrm{B} / \mathrm{C}$ foi a torta de algodão $(1,16)$, apresentando uma maior atratividade do sistema.

Tabela 9. Análise de sensibilidade dos sistemas de confinamento que utilizam diferentes fontes proteicas alternativas na ração concentrada

\begin{tabular}{lcccc}
\hline \multirow{2}{*}{ Variável } & \multicolumn{4}{c}{ Fonte proteica principal na ração } \\
\cline { 2 - 5 } & $\mathrm{SOJ}_{100}$ & $\mathrm{TA}_{51,8}$ & $\mathrm{UR}_{100}$ & $\mathrm{LEU}_{100}$ \\
\hline Relação Benefício/Custo & 1,12 & 1,16 & 1,03 & 1,00 \\
Taxa Interna de Retorno (\%) & 25,80 & 33,46 & 10,99 & 6,95 \\
Valor Presente Líquido (R\$) & 75219,86 & 105612,16 & 16420,41 & 330,23 \\
\hline
\end{tabular}

$\mathrm{LEU}_{100}$ : feno do folíolo da leucena (100\% substituindo o farelo de soja), $\mathrm{TA}_{51,8}$ : torta de algodão $(51,8 \%$ substituindo o farelo de soja), SOJ $_{100}\left(100 \%\right.$ de farelo de soja como fonte proteica), UR $_{100}(100 \%$ substituindo o farelo de soja). 
Os piores valores de taxa interna de retorno (TIR) e valor presente líquido (VPL) foram verificados no sistema de confinamento onde os cordeiros foram alimentados com $\mathrm{LEU}_{100}$, apresentando uma TIR de $6,95 \%$ e um VPL de R\$ 330,23 para uma taxa de juros de $6,87 \%$ ao ano. Isto se deve principalmente ao baixo desempenho produtivo observado pelos animais alimentados com esta fonte proteica em relação às demais analisadas, o que proporciona uma menor venda anual do quilograma de peso corporal do cordeiro, gerando uma menor receita anual, tornando a atividade menos atrativa. Contudo, mesmo tendo apresentado os piores índices, estes foram suficientes para compensar os custos de oportunidade de sacrificar outras alternativas de investimento, tornando o investimento economicamente viável.

O sistema de produção com cordeiros alimentados com $\mathrm{TA}_{51,8}$ apresentaram os melhores valores econômicos com $\mathrm{B} / \mathrm{C}>1,0$; VPL $>0$, mesmo com um valor de venda do quilograma de peso corporal similar aos demais tratamentos. Ademais, a TIR mostrou-se maior $(33,36 \%)$ do que a taxa de juros de oportunidade do capital, tornando o investimento nessa atividade rentável, o que proporciona um melhor retorno do capital investido na atividade.

Rações utilizando torta de algodão substituindo o farelo de soja em 51,8\% em confinamentos utilizando feno de capim-elefante proporcionam um maior ganho de peso aos animais em comparação às demais fontes proteicas avaliadas neste estudo, favorecendo ao menor período de confinamento necessário para o ganho de peso desejável em sistemas de terminação de cordeiros mestiços Morada Nova, permitindo uma maior rotatividade do sistema, proporcionando uma melhor viabilidade econômica da atividade.

\section{REFERÊNCIAS}

ACEDO, T.S.; PAULINO, M.F.; DETMANN, E.; VALADARES FILHO, S.C.; SALES, M.F.L.; PORTO, M. O. Fontes proteicas em suplementos para novilhos no período de transição secaáguas: características nutricionais.

Arquivos Brasileiros de Medicina Veterinária e Zootecnia, v.63, n.4, p.895-904, 2011.

ARAÚJO FILHO, J.T.; COSTA, R.G.; FRAGA, A.B.; SOUSA, W.H.; CEZAR, M.F.; BATISTA, A.S.M. Desempenho e composição da carcaça de cordeiros deslanados terminados em confinamento com diferentes dietas. Revista Brasileira de Zootecnia, v.39, n.2, p.363-371, 2010.

CARVALHO, G.G. P.; PIRES, A.J. V.; SILVA, R.R.; VELOSO, C.M.; SILVA, H. G.O. Comportamento ingestivo de ovinos alimentados com dietas compostas de silagem de capim-elefante amonizada ou não e subprodutos agroindustriais.

Revista Brasileira de Zootecnia, v.35, n.4, p.1805-1812, 2006.

COSTA, R.G.; ANDRADE, M.G.L.P.; MEDEIROS, G.R.; AZEVEDO, P.S.; MEDEIROS, A.N.; PINTO, T.F.; SOARES, J.N.; SUASSUNA, J.M.A. Características de carcaça de ovinos Santa Inês e Morada Nova abatidos com diferentes pesos. Actas Iberoamericanas de Conservación Animal, v.1, p.231234, 2011.

CUNHA, M.G.G.; CARVALHO, F.F.R.; VÉRAS, A.S.C.; BATISTA, A.M.V.

Desempenho e digestibilidade aparente em ovinos confinados alimentados com dietas contendo níveis crescentes de caroço de algodão integral. Revista Brasileira de Zootecnia, v.37, n.6, p.1103-1111, 2008. 
Rev. Bras. Saúde Prod. Anim., Salvador, v.15, n.3, p.717-730 jul./set., 2014 http://www.rbspa.ufba.br ISSN 15199940

HOFFMANN, R.; ENGLER, J.J. C.; SERRANO, O.; THANE, A.C.M.; NEVES, E.M. Administração da empresa agrícola. 5. ed. São Paulo: Pioneira, 1987, 325 p.

FELISBERTO, N.R.O.; RODRIGUES, M.T.; BOMFIM, M.A.D.; MATOS, R.S.; CORDEIRO, A.G.P. C.; SILVA, M.M.C. Effects of different sources of protein on digestive characteristics, microbial efficiency, and nutrient flow in dairy goats. Revista Brasileira de Zootecnia, v.40, p.2228-2234, 2011.

MARTIN, N.B.; OLIVEIRA, M.D.M; ÂNGELO, J.A.; OKAWA, H. Sistema integrado de custos agropecuários CUSTAGRI. Informações

Econômicas, v.28, n.1, p.7-27, 1998.

NATIONAL RESEARCH COUNCIL NRC. Nutrient requirements of the dairy cattle. 7.ed. Washington, 2001. $363 p$.

NATIONAL RESEARCH COUNCIL NRC. Nutrient requirements of small ruminants. New York: National Academy of Sciences, 2007. 362p.

PIRES, A. V.; OLIVEIRA JÚNIOR, R. C.; FERNANDES, J. J. R.; SUSIN, I.; SANTOS, F. A. P.; ARAÚJO, R. C.; GOULART, R. C. D. Substituição do farelo de soja por ureia ou amireia na dieta de bovinos de corte confinados. Pesquisa Agropecuária Brasileira, v.39, n.9, p.937-942, 2004.

PIRES, A.J.V.; REIS, R.A.; CARVALHO, G.G.P.; SIQUEIRA, G.R.; BERNARDES, T.F.; RUGGIERI, A.C.; ALMEIDA,E.O.; ROTH, M.T. Degradabilidade ruminal da matéria seca, da fração fibrosa e da proteína bruta de forrageiras. Pesquisa

Agropecuária Brasileira, v.41, n.4, p.643-648, 2006.
POSSENTI, R.A.; FRANZOLIN, R.; SCHAMMAS, E.A.; DEMARCHI, J.J.A.A.; FRIGHETTO, R.T.S.; LIMA, M.A. Efeitos de dietas contendo Leucaena leucocephala e Saccharomyces cerevisiae sobre a fermentação ruminal e a emissão de gás metano em bovinos. Revista Brasileira de Zootecnia, v.37, n.8, p.1509-1516, 2008.

SANTOS, F.A.P.; SANTOS, J.E.P.; THEURER, C.B. HUBER, J.T. Effects of rumen degradable protein on dairy cow performance: A 12-year literature review. Journal of Dairy Science, v.81, n.2, p.3182-3213, 1998.

SAS INSTITUTE. Version 9.3. Cary: SAS Institute Inc. 2011. 1 CD-ROM.

SILVA, D.J.; QUEIROZ, A.C. Análises de alimentos: métodos químicos e biológicos. 3.ed. Viçosa, MG: Universidade Federal de Viçosa. 2002. $235 p$.

VÉRAS, R.M.L.; FERREIRA, M.A.; CAVALCANTI, C.V.A. VÉRAS, A.S.C.; CARVALHO, F.F.R.; SANTOS, G.R.A.; ALVES, K.S.; MAIOR JÚNIOR, R.J.S. Substituição do milho por farelo de palma forrageira em dietas de ovinos em crescimento. Desempenho. Revista brasileira de Zootecnia, v.34, n.1, p.249-256, 2005.

Data de recebimento: 03/12/2013

Data de aprovação: 23/09/2014 